\title{
Políticas linguísticas para surdos em países lusófonos
}

\author{
Fabiany Corrêa Basoni ${ }^{1}$ \\ Curso de Letras - Lic. em Língua Portuguesa e Literaturas, Centro de Ciências Humanas e Naturais, \\ Universidade Federal do Espírito Santo, Vitória, ES, Brasil
}

Pedro Henrique Witchs ${ }^{2}$

Departamento de Línguas e Letras, Programa de Pós-Graduação em Linguística, Universidade Federal do Espírito Santo, Vitória, ES, Brasil

Resumo: Em diferentes países, pessoas surdas constituem minorias linguísticas cujas condições para o uso de suas línguas não são favoráveis. Este artigo objetiva discutir políticas linguísticas para surdos em países de língua portuguesa. Com base em autores da Política Linguística, bem como dos Estudos Surdos, a partir de uma pesquisa qualitativa e exploratória do tipo documental, buscou-se analisar documentos oficiais que regulamentam o uso e o ensino de línguas de sinais em oito países lusófonos. Observouse que, em pelo menos metade desses países, as línguas de sinais permanecem oficialmente invisíveis; em alguns casos, embora já comecem a ser documentadas, seu uso e ensino não estão legalmente amparados. Considera-se, nesse sentido, que políticas linguísticas para surdos constituem um direito humano inalienável. Apesar de não serem suficientes, tais políticas são necessárias para a formação linguística e cultural dos surdos, propiciando cenários nos quais eles possam exercer seus direitos à aquisição de língua, à liberdade de comunicação e de expressão e às condições de igualdade.

Palavras-chave: Línguas de sinais; Políticas linguísticas; Países lusófonos.

Title: Language policies for deaf people in lusophone countries

Abstract: In different countries, deaf people are linguistic minorities for whom the conditions of use of languages are not favorable. Therefore, this paper intents to discuss political linguistics for deaf people in Portuguese speaking countries. Based on Language Policy and Deaf Studies authors, it analyzes official documents that regulate the use and the teaching of sign languages in eight lusophone countries. It was observed that no less than in half of the searched countries, the sign languages remain officially invisible; in some cases, although some languages begin to get documented, their use and teaching are yet to be legally supported. Therefore, in this sense, it is deemed that language policies for the deaf constitute an inalienable human right. While they may not be enough, such policies are necessary for the linguistic and cultural formation of deaf people, providing scenarios in which they shall exercise their rights to language acquisition, freedom of speech and equality conditions.

Keywords: Sign language; Language policies; Lusophone countries.

\footnotetext{
${ }^{1}$ Graduanda em Letras - Língua Portuguesa e Literaturas pela Universidade Federal do Espírito Santo. Orcid: http://orcid.org/0000-0002-9611-9756. E-mail: fbasonif@gmail.com.

2 Doutor em Educação pela Universidade do Vale do Rio dos Sinos. Professor do Departamento de Línguas e Letras e do Programa de Pós-Graduação em Linguística da Universidade Federal do Espírito Santo. Orcid: http://orcid.org/0000-0003-0850-2366. E-mail: pedro.witchs@ufes.br.
} 


\title{
Introdução
}

\begin{abstract}
Nos últimos 30 anos, as comunidades surdas alcançaram um nível de consciência e assertividade política pelo qual se tornaram capazes de perseguir legislações para reconhecer a(s) língua(s) de sinais de seus países. Pela via do reconhecimento da língua de sinais, os surdos costumam colher benefícios de várias maneiras, desde acesso a empregos a provisões educacionais, mas se não colherem, no mínimo, a língua de sinais se torna legítima aos olhos da sociedade por ser qualificada para créditos universitários ou reconhecida como uma língua. Para entender completamente o impacto do reconhecimento da língua de sinais, precisamos primeiro perceber que existem vários níveis de reconhecimento e estar cientes dos diferentes impactos da política em cada nível. (HLIBOK, 2018, p. 55) ${ }^{3}$
\end{abstract}

Apesar de Hlibok (2018) destacar os esforços das comunidades surdas nas últimas três décadas, é importante ressaltar que o movimento surdo em prol da língua de sinais ${ }^{4}$ tem sido observado desde o século XIX. A origem desse movimento é remetida ao ano de 1834, pelo sociólogo francês Mottez (1989 apud BENVENUTO; SÉGUILLON, 2016), quando os surdos iniciaram um culto ao abade Michel de l'Épée ${ }^{5}$ como forma de fortalecer o direito da fala sinalizada. Entretanto, é após a publicação do trabalho de Stokoe (2005) em 1960 - no qual o linguista descreveu estruturas linguísticas do sistema de comunicação visual dos surdos estadunidenses e defendeu o argumento de que esse sistema se tratava de uma língua no sentido pleno do termo - que as línguas de sinais passaram a ser interpretadas por outras condições epistemológicas.

A entrada das línguas de sinais na grade de inteligibilidade da Linguística moderna reverberou significativamente no uso dessas línguas pela educação de surdos. Na atualidade, os estudos linguísticos das línguas de sinais, aliados a pesquisas em educação de surdos, formam a base da tendência filosófico-pedagógica que ficou conhecida como bilinguismo para surdos. Nesse sentido, a educação bilíngue para surdos tem compreendido o uso da língua de sinais como primeira língua e língua de instrução, e o uso da língua oral nacional como segunda língua na modalidade escrita.

O objetivo deste artigo é discutir políticas linguísticas para surdos no contexto específico dos países caracterizados como países de língua portuguesa. Dessa forma, queremos retomar a importância de perceber a diferença de níveis de reconhecimento linguístico como sugere Hlibok (2018). Para tanto, a partir de perspectivas teóricas oriundas

\footnotetext{
${ }^{3}$ Tradução nossa do original em inglês: "In the past 30 years or so, Deaf communities have reached a level of political awareness and assertiveness where they are able to pursue legislation and/or laws to recognize the sign language(s) of their country. By the avenue of sign language recognition, Deaf people often reap benefits in various ways, from employment access to educational provisions, but if not, at the minimum, the sign language becomes legitimate in the society's eyes via being qualified for college credits or recognized as a language. To fully understand the impact of sign language recognition, we first must realize that there are several levels of recognition and be aware of the different impact of policy with each level" (HLIBOK, 2018, p. 55).

${ }^{4}$ Em alguns casos, no decorrer deste artigo, a língua de sinais será tratada como língua gestual, de modo a respeitar a variação utilizada por alguns países lusófonos.

${ }^{5}$ Fundador da primeira escola para surdos em Paris no século XVIII. L'Épée defendia o uso do método misto na educação de surdos, o que consistia na utilização dos sinais manuais para ensinar crianças surdas a ler, escrever e, eventualmente, falar.
} 
do campo da Política Linguística e do campo dos Estudos Surdos, analisamos documentos oficiais que regulamentam o uso e o ensino de línguas de sinais em oito países lusófonos, a saber: Angola, Brasil, Cabo Verde, Guiné-Bissau, Moçambique, Portugal, São Tomé e Príncipe, e Timor-Leste.

O texto está organizado como segue: após esta breve introdução, caracterizamos o histórico lugar ocupado pelas línguas de sinais no contexto lusófono; na sequência, descrevemos o percurso metodológico da pesquisa em políticas linguísticas na perspectiva transnacional; posteriormente, analisamos os principais resultados encontrados no mapeamento das políticas de línguas de sinais; por fim, argumentamos que a existência de políticas linguísticas para surdos é necessária, porque legitima o direito a condições de igualdade, porém não suficiente, uma vez que não garante a imediata transformação do comportamento de uma população perante ao uso das línguas de sinais em diversas sociedades.

\section{Minha pátria é a língua portuguesa: as línguas de sinais em países lusófonos}

Rememoramos a célebre frase de Bernardo Soares, heterônimo de Fernando Pessoa, minha pátria é a língua portuguesa, publicada originalmente em 1931. A despeito de análises literárias sobre esse texto, simbolicamente, ele retrata o esforço empreendido na construção da ideia de lusofonia. De acordo com Freixo (2009), essa construção, aliada ao empenho do Estado português na criação da Comunidade de Países de Língua Portuguesa (CPLP), pode ser relacionada a uma reinvenção do Império por meio da língua. Ao focalizarmos os jogos políticos que envolvem o desejo de unificação da língua portuguesa e o poder associado à constituição de uma língua nacional, perguntamos: qual é o lugar ocupado pelas línguas de sinais no cenário lusófono?

Para tentarmos responder a essa pergunta, consideramos importante recuperar a memória sobre a experiência da surdez na Europa do século XVIII. É nesse contexto histórico que a surdez começa a se constituir como um problema do Estado e surgem as primeiras instituições voltadas ao ensino dos surdos-mudos ${ }^{6}$. A educação de surdos, nesse período, esteve centrada no ensino da língua falada, na leitura e na escrita, e muitos foram os debates, em congressos nacionais e internacionais realizados no decorrer do século XIX e XX, sobre os métodos mais eficazes para que esse ensino acontecesse. Sobre essa questão, destacamos o Primeiro Congresso Nacional para o Melhoramento das Condições dos SurdosMudos, na cidade de Lyon em 1879 (RODRIGUES; VIEIRA-MACHADO, 2019).

As discussões em torno da educação de surdos, ainda no século XVIII, colocaram em evidência as línguas de sinais utilizadas por surdos; e o início de sua escolarização marca um processo de interferência ouvinte nessas línguas. Ao se inteirar da língua de sinais natural utilizada por surdos parisienses - conhecida como antiga língua de sinais francesa l'Épée sentiu necessidade de incorporar a ela gestos que pudessem equivaler a estruturas

\footnotetext{
${ }^{6}$ Termo usado na época para se referir às pessoas surdas que não falavam uma língua de modalidade oralauditiva.
} 
próprias da língua francesa, conforme explica Carvalho (2012), transformando para sempre o que hoje conhecemos como a língua de sinais francesa (LSF). A constituição da língua gestual portuguesa (LGP) e da língua brasileira de sinais (Libras) reserva semelhanças dessa natureza em suas histórias.

A educação de surdos, em Portugal, remonta ao ano de 1823, com a fundação do Instituto Real de Surdos-Mudos e Cegos pelo sueco Per Aron Borg. A comunicação em sinais usada pelas crianças surdas portuguesas que ingressavam na instituição, "em conjunto com a língua gestual de instrução utilizada por Per Aron Borg, fornecia as primeiras bases do que seria a LGP" (CARVALHO, 2016, p. 16). No caso brasileiro, a fundação do Colégio Nacional para Surdos-Mudos de Ambos os Sexos, em 1856, pelo francês Edouard Huet, possibilitou a influência da LSF sobre a comunicação sinalizada das crianças surdas brasileiras, constituindo o que hoje é a Libras.

Nos países africanos de língua portuguesa e em Timor-Leste, entretanto, esse processo de institucionalização das línguas de sinais - isto é, esse envolvimento da língua de sinais com uma instituição educacional - teve início nos séculos XX e XXI. É importante destacar que, nesses países, ao contrário do que acontece em Brasil e em Portugal, o português não é a primeira língua da maioria da população. Por serem países de independência mais recente, segundo Vanali (2016, p. 161), “a opção pelo português como língua oficial correspondeu à necessidade de, por um lado, assegurar equilíbrios internos e, por outro, melhor posicionar o país na ordem internacional". Esses processos históricos refletem-se, como veremos, na constituição das línguas de sinais utilizadas nesses países.

Em Moçambique, segundo Bavo e Coelho (2019), a educação de surdos emergiu com a criação de escolas especiais particulares em 1962. Apesar disso, as autoras afirmam que a menção à língua de sinais moçambicana (LSM) aconteceu apenas em 1990. Entretanto, "os censos populacionais de 1997, 2007 e 2017, não registraram a existência da LSM na distribuição e diversidade linguística do país" (BAVO; COELHO, 2019, p. 911). Em Angola, a educação especial caracterizada por ser particular e dedicada ao atendimento a cegos, conforme Viúme (2013), constituiu-se na década de 1970, ainda no sistema colonial. Após a independência do país, na década de 1980, a educação especial se tornou uma modalidade de ensino público e começou a abarcar a educação de surdos. Contudo, em 2004, o Instituto Nacional para a Educação Especial implementa o Projecto para o Estudo Desenvolvimento e Uniformização da Língua Gestual Angolana (LGA) (VIÚME, 2013).

Em Cabo Verde, a educação de surdos começou a adquirir expressividade em 1996. De acordo com Tavares (2013), com o retorno do jovem surdo Jonas Timas, que se escolarizou em Portugal, a Associação de Apoio ao Desenvolvimento e Integração das Crianças Deficientes (AADICD) decidiu formar turmas de educação de surdos. Até 2013, a autora afirmava inexistir "uma língua gestual cabo-verdiana e [...] professores surdos para atuar como professores de língua gestual" (TAVARES, 2013, p. 68).

Na Guiné-Bissau, segundo Martins (2013), foi no ano de 2003 que um número maior de surdos se agrupou sob uma instituição educacional. Na Escola Bengala Branca, da Associação Guineense para Reabilitação e Integração dos Cegos (AGRICE), e com o apoio da 
Associação Portuguesa de Surdos (APS), começou-se a observar certa unificação linguística da comunidade surda guineense. No caso de São Tomé e Príncipe, de acordo com Palha e Mineiro (2019), até 2013, os surdos não frequentavam escolas e não havia uma língua de sinais em comum entre eles, e entre eles e seus possíveis professores. Para dar conta das demandas socioeconômicas dessa população, o Governo de São Tomé e Príncipe, em conjunto com o Instituto Marquês de Valle Flôr, solicitou apoio à Universidade Católica Portuguesa para promover, conforme Mineiro e Carmo (2016, p. 162), "as bases para que emergisse uma língua gestual para crianças surdas".

Já em Timor-Leste, único país asiático que tem a língua portuguesa como uma de suas duas línguas oficiais e um dos países independentes mais recentes do mundo, a educação de surdos tem início em 1982, de acordo com Santos e Sousa (2017). Segundo os autores, a educação de surdos se desenvolvia com o uso da língua gestual indonésia oriunda de Jacarta. Apesar de não haver uma língua gestual de Timor-Leste oficialmente em uso no país, a comunicação em uma das instituições dedicadas à educação de surdos acontece "através de uma mescla linguística baseada da Língua Gestual Americana, Língua Gestual Filipina e ainda de alguns gestos nativos" (SANTOS; SOUSA, 2017, p. 112).

A partir dessa contextualização histórica que nos permite visualizar, ainda que de forma muito breve, a emergência e o lugar ocupado pelas línguas de sinais nos países de língua portuguesa, intentamos evidenciar a conjuntura que iremos desenvolver no decorrer deste artigo. Para tanto, a seguir, descrevemos o percurso metodológico da pesquisa que oportunizou essa discussão.

\section{A pesquisa em políticas de línguas de sinais na perspectiva transnacional}

A discussão aqui apresentada foi possível a partir de uma pesquisa em andamento cujo objetivo é mapear políticas linguísticas para surdos em uma perspectiva transnacional. Por perspectiva transnacional, neste contexto, entendemos o recorte analítico com foco nos países cujas línguas oficiais, que por sua vez são de modalidade oral-auditiva, constituem-se como línguas transnacionais, como no caso dos países de língua portuguesa. A pesquisa se desenvolve pela análise que opera sobre o eixo da gestão linguística. Esse eixo é caracterizado por Spolsky (2016, p. 36) como "o esforço observável e explícito realizado por alguém ou por algum grupo que tem ou afirma ter autoridade sobre os participantes de um domínio para modificar suas práticas ou crenças".

Portanto, apesar de concordarmos que as políticas linguísticas não podem ser reduzidas, como propõe Calvet (2007, p. 11), à "determinação das grandes decisões referentes às relações entre as línguas e a sociedade", neste artigo, entendemos que elas também podem ser observadas em documentos que, de algum modo, regulamentam o comportamento linguístico de um grupo. Considerando o escopo da análise que propomos realizar, optamos por explorar essa conjuntura a partir de documentos oficiais que reconhecem legalmente as línguas de sinais e que estabelecem outras providências a elas relacionadas. 
Nesse sentido, a materialidade analisada foi constituída por um conjunto de políticas explícitas de reconhecimento legal de línguas de sinais oriundas de oito países que, embora apresentem uma diversidade linguística, são tratados como países de língua portuguesa. Como já mencionado anteriormente, eles são: Angola, Brasil, Cabo Verde, Guiné-Bissau, Moçambique, Portugal, São Tomé e Príncipe, e Timor-Leste. Excetuam-se desse recorte as comunidades de falantes do português como em Goa, Diu, Damão, na Índia; Málaca, na Malásia; Macau, na China; e Zanzibar, na Tanzânia. No Quadro 1 abaixo, listamos os países e os documentos oficiais que constituem o material de análise.

Quadro 1 - Material de análise

\begin{tabular}{|l|l|}
\hline País & Documentos oficiais que tratam de língua de sinais \\
\hline Angola & $\begin{array}{l}\text { Resolução no 1/13: Convenção sobre os Direitos das Pessoas com Deficiência } \\
\text { Lei Federal no 10/16 }\end{array}$ \\
\hline Brasil & $\begin{array}{l}\text { Lei Federal no 10.436/2002 } \\
\text { Decreto no 5.626/2005 }\end{array}$ \\
\hline Cabo Verde & Documentos oficiais não localizados \\
\hline Guiné-Bissau & Documentos oficiais não localizados \\
\hline Moçambique & Constituição da República de Moçambique de 2005 (Art. 125) \\
\hline Portugal & $\begin{array}{l}\text { Constituição da República Portuguesa - Revisão de 1997 (Art. 74) } \\
\text { Decreto-Lei no 3/2008 } \\
\text { Lei no 21/2008 }\end{array}$ \\
\hline São Tomé e Príncipe & Documentos oficiais não localizados \\
\hline Timor-Leste & Documentos oficiais não localizados \\
\hline
\end{tabular}

Fonte: elaborado pelos autores (2020).

Como é possível observar, na busca pelos materiais de análise, foram localizados oito documentos oficiais que, de algum modo, regulamentam o uso de línguas de sinais em quatro países: Angola, Brasil, Moçambique e Portugal. Não foram localizados documentos oficiais que regulamentem o uso de línguas de sinais em Cabo Verde, Guiné-Bissau, São Tomé e Príncipe e Timor-Leste. A busca e a seleção desse material envolveram o que está disponível nas páginas oficiais dos governos desses países na internet. A decisão por

\footnotetext{
7 Uma ressalva metodológica acerca de documentos relativos à Convenção dos Direitos da Pessoa com Deficiência: de todos os países pesquisados, apenas Timor-Leste ainda não aderiu à Convenção. São signatários desde 2007: Brasil, que a ratificou em 2008; Cabo Verde, que a ratificou em 2011; Moçambique, que a ratificou em 2012; e Portugal, que a ratificou em 2009. Guiné-Bissau é signatário desde 2013 e a ratificou em 2014. Angola e São Tomé e Príncipe, embora não sejam signatários, aderiram à Convenção, respectivamente, em 2014 e 2015. Observamos que os documentos de Brasil e Portugal que ratificam a Convenção não incorporam novidades aos documentos selecionados nesses países; também não localizamos os documentos de Cabo Verde, Guiné-Bissau, Moçambique e São Tomé e Príncipe que ratificam a Convenção. Como a Resolução no 1/13 foi localizada e contempla um elemento de política linguística para surdos, optamos por incluí-la ao caso de Angola.
} 
restringir a análise aos documentos jurídicos e políticos se justifica pela razão de estes documentos serem, por excelência, regulamentadores oficiais das práticas sociais de um Estado-Nação.

Durante a busca, entretanto, encontramos notícias, relatos de pesquisa e materiais didáticos que serviram de pistas para compreendermos a situação das línguas de sinais de alguns dos países cujos documentos oficiais não tinham sido localizados até o momento da escrita deste artigo. A sistematização do material envolveu a produção de quadros esquemáticos transnacionais que auxiliaram no processo analítico. Na sequência, passamos a discutir e analisar os resultados obtidos a partir dessa pesquisa.

\section{Políticas linguísticas para surdos nos países de língua portuguesa}

É importante reiterar que o movimento de reconhecimento legal e de promoção e difusão das línguas de sinais, ao redor do mundo, ancora-se em um conjunto de fatores sociais e políticos mobilizados na segunda metade do século XX. Como já mencionado anteriormente, nesse período, vemos uma ascensão da expressão política das pessoas com deficiência e, no escopo desse movimento, mas com pautas específicas em relação a seus direitos linguísticos, das pessoas com surdez. Aliado a isso, tem-se a Declaração Universal dos Direitos Linguísticos, convencionada em Barcelona no ano de 1996, a partir da qual é relacionada uma série de direitos individuais inalienáveis vinculados ao uso da própria língua como o ensino da própria língua e da própria cultura; a presença equitativa da língua nos meios de comunicação; e o atendimento na própria língua pelos organismos oficiais e nas relações socioeconômicas.

Vale destacar que as políticas linguísticas para surdos, conforme Bär, Rodrigues e Souza (2018, p. 108), "têm sido, tanto no cenário nacional quanto internacional, conduzidas no âmbito das políticas públicas para pessoas com deficiência". De acordo com as autoras, de certa forma, isso marca uma ambivalência discursiva nos documentos oficiais, que passam a vincular a condição bilíngue dos surdos a uma noção de surdez reduzida à patologia de impedimento auditivo (BÄR; RODRIGUES; SOUZA, 2018). Isso contribui para a compreensão sobre o papel da Convenção Internacional sobre os Direitos da Pessoa com Deficiência, adotada pela Assembleia Geral das Nações Unidas no final de 2006, no que tange às línguas de sinais. No art. 21 do texto da Convenção, que expõe medidas para assegurar a liberdade de expressão e opinião das pessoas com deficiência, é exigido dos Estados Partes da Organização das Nações Unidas (ONU) que se aceite e facilite o uso de línguas de sinais em trâmites oficiais, bem como que ele seja reconhecido e promovido em seus territórios nacionais.

Além desses fatores acima mencionados, é preciso registrar também o esforço da World Federation of the Deaf (WFD) que, de acordo com Quadros (2018), tem apoiado as organizações nacionais de surdos na luta pelo reconhecimento de suas línguas de sinais nacionais. Considerando essa conjuntura, De Meulder (2015) havia registrado, até 2014, o reconhecimento de línguas de sinais em aproximadamente 31 países membros das Nações 
Unidas. A partir desse reconhecimento explícito, a autora conseguiu distinguir cinco categorias que variam de acordo com as especificidades dos contextos nacionais como a legislação e a atitude em relação à diversidade cultural e linguística. Essas categorias podem ser caracterizadas da seguinte forma: i) reconhecimento constitucional; ii) reconhecimento por meio de legislação geral de línguas; iii) reconhecimento por meio de uma lei de língua de sinais; iv) reconhecimento por meio de uma lei de língua de sinais que inclui outros meios de comunicação; e v) reconhecimento por meio de legislação sobre o funcionamento de um conselho nacional de línguas.

Além das categorias de reconhecimento explícito, a autora ainda sugere mais três categorias para distinguir o reconhecimento legal implícito de línguas de sinais em alguns países: uma que envolva a menção da língua de sinais na legislação sobre deficiência, igualdade ou educação; uma que envolve o reconhecimento concedido por uma declaração ou decisão governamental; e outra que diz respeito ao reconhecimento restrito às esferas estaduais ou municipais (DE MEULDER, 2015). Nesse caso, importa destacar que, no material analisado, nem todas as línguas de sinais usadas em um território nacional passam pelo processo de reconhecimento legal. Portanto, nos casos em que há um reconhecimento, muitas vezes, ele normalmente se refere a uma língua de sinais usada pelas comunidades de pessoas surdas dos grandes centros urbanos. Um exemplo disso, é a língua de sinais urubukaapor (FERREIRA-BRITO, 1984), e outras variedades de língua de sinais usadas por surdos indígenas ou em comunidades isoladas, que ainda estão em fase de documentação no Brasil, como as línguas de sinais de Fortalezinha e de Porto de Galinhas (FUSELLIER-SOUZA, 2004), a língua de sinais de caiçara (TEMÓTEO, 2008), a língua de sinais kaingang (GIROLETTI, 2008), a língua de sinais cena (PEREIRA, 2013), a língua de sinais sateré-waré (AZEVEDO, 2015), a língua de sinais pataxó (DAMASCENO, 2017 apud QUADROS, 2019) e a língua de sinais terena e guarani (VILHALVA, 2012).

Nas subseções seguintes, apresentamos a análise dos materiais selecionados dos países envolvidos na pesquisa, considerando o reconhecimento explícito e implícito das línguas de sinais nesses documentos. De modo a organizar a discussão, o que segue está subdividido por cada um dos países.

\section{A língua gestual angolana}

O contexto angolano de reconhecimento da língua de sinais, implicitamente, inicia em 2004, como mencionado anteriormente, com um projeto de desenvolvimento e uniformização da língua gestual angolana (LGA), conduzido pelo Instituto Nacional para a Educação Especial. Mais tarde, ao aderir à Convenção sobre os Direitos das Pessoas com Deficiência da ONU, de 2006, o Governo de Angola publica, em 2013, a Resolução no 1/13. Esse documento com 50 artigos abarca questões sobre a garantia e a proteção dos direitos das pessoas com deficiência a todas as seções da vida cidadã angolana, além de reforçar a proibição da discriminação em relação a elas. No que tange à língua gestual, o documento caracteriza, em seu art. 2o, linguagem como a inclusão da linguagem falada, da língua 
gestual e de outras formas de comunicação não faladas, mas não há uma descrição ou caracterização do que se entende por língua gestual.

O documento também caracteriza a educação bilíngue, em seu art. 24으, Educação, como uma "facilitação da aprendizagem de língua gestual e promoção da identidade linguística da comunidade surda" (p. 94). Apesar dessas menções à língua gestual e à educação bilíngue para surdos, na Resolução não ficam evidentes as formas de implementação do ensino da LGA, nem é previsto o ensino dessa língua na formação de professores, assim como também não há menção a uma formação de tradutores e intérpretes da língua gestual.

Em 2016, tem-se a publicação da Lei no 10/16, nomeada Lei das Acessibilidades, que abrange questões acerca da promoção da acessibilidade, tendo como desígnio a eliminação de barreiras, e o acesso às pessoas com deficiência. Essa lei descreve, na alínea gg) de seu art. 5ㅇ, intitulado Definições, a língua gestual como uma "forma de comunicação e expressão em que o sistema linguístico de natureza visual-motora, com estrutura gramatical própria, constitui um sistema linguístico de transmissão de ideias e fatos, oriundos de comunidades de pessoas surdas de Angola" (p. 3141). Além disso, a Lei também reconhece a LGA e outros recursos de expressão a ela associados.

Ainda na mesma lei, registra-se a garantia da inclusão do ensino da LGA como parte integrante dos planos e programas de ensino nos níveis básico, médio e superior e nos cursos de formação de professores. Além disso, o documento destaca que a língua gestual não pode substituir a modalidade escrita da língua portuguesa. Nas categorias de De Meulder (2015), a LGA teria sido implicitamente reconhecida na legislação sobre deficiência, igualdade e educação. Contudo, entendemos que, apesar do reconhecimento ser registrado na Lei das Acessibilidades, ele está bem demarcado e explícito, compreendendo um dos artigos que constituem tal lei.

\section{A língua brasileira de sinais}

No contexto brasileiro, é possível encontrar uma extensa bibliografia, principalmente oriunda da área da Educação, que analisa a documentação política relacionada à Libras. Essas análises podem ser encontradas em produções desenvolvidas por Bär, Rodrigues e Souza (2018); Santos, Coelho e Klein (2017); Thoma (2016); Rodrigues e Beer (2016); Nascimento e Lacerda (2016); Lodi (2013); Quadros e Campello (2010); e muitos outros. Apesar da existência anterior de legislação sobre acessibilidade que mencione a língua de sinais no Brasil, optamos por selecionar dois principais documentos para esta análise: a Lei Federal no 10.436, de 2002, também conhecida como Lei de Libras; e o Decreto Federal no 5.626 , de 2005, que regulamenta tal lei.

É a partir da Lei de Libras que essa língua é reconhecida como uma língua nacional usada pelas comunidades surdas do Brasil. Nota-se que o texto desse documento pode ter influenciado a redação do artigo que reconhece a língua gestual angolana na Lei das Acessibilidades, já que ambos são praticamente iguais, sobretudo na definição da língua de 
sinais como "forma de comunicação e expressão, em que o sistema linguístico de natureza visual-motora, com estrutura gramatical própria, constitui um sistema linguístico de transmissão de ideias e fatos, oriundos de comunidades de pessoas surdas do Brasil” (p. 23). No que diz respeito à educação de surdos, em seu art. 4으, é disposta a inclusão da Libras como componente curricular em cursos de Educação Especial, Fonoaudiologia e Magistério. Em parágrafo único, como acontece com a LGA, destaca-se que a Libras não pode substituir a modalidade escrita da língua portuguesa.

Apesar do reconhecimento legal em uma lei de língua de sinais, como a categoria de De Meulder (2015), é somente com o Decreto $n=5.626$ que a Lei $n=10.436$ é regulamentada, instituindo exigências para o Estado quanto ao ensino e ao uso da Libras. O documento mantém o disposto no art. 4o da Lei de Libras, sobre a inclusão da disciplina curricular obrigatória nos cursos de formação de professores, a nível médio e superior, e nos cursos de Fonoaudiologia, contemplando instituições de ensino públicas e privadas. Ademais, o documento também institui a formação superior de professores de Libras, viabilizando uma educação bilíngue que tem a Libras como primeira língua, e o português escrito, segunda. Esse decreto também prevê a exigência de criação de cursos de formação de tradutores e intérpretes de Libras, considerando a oportunidade de acesso comunicacional de surdos além do contexto educacional.

\section{A língua gestual cabo-verdiana}

Como já mencionado antes, não foi possível localizar documentos oficiais que regulamentem a língua gestual cabo-verdiana. Nas buscas pelos canais oficiais do governo, identificamos que a Constituição da República de Cabo Verde, aprovada em 1992, apesar de não fazer menção direta à língua de sinais do país nem à educação bilíngue, apresenta um artigo sobre os direitos dos portadores de deficiência, no qual é incumbido aos poderes públicos promover condições econômicas, sociais e culturais que facilitem a participação desses sujeitos na vida ativa; garantir a eliminação de barreiras arquitetônicas e outras de acesso a instalações públicas e a equipamentos sociais; bem como organizar, fomentar e apoiar a integração das pessoas com deficiência no ensino e na formação técnicoprofissional.

Embora não tenhamos encontrado documentação oficial sobre a língua gestual caboverdiana, foi possível acessar informações sobre o Projeto de Cooperação Técnica Internacional "Escola de Todos", realizado pela parceria entre os governos de Cabo Verde e do Brasil, e tendo como instituição executora a Universidade Federal de Santa Maria (UFSM). Esse projeto envolveu, em 2013, a construção e o desenvolvimento de um dicionário para padronização da língua gestual em Cabo Verde, que tem forte influência da LGP. Conforme Pavão, Gomes e Casarin (2019) descrevem, dada a situação topográfica do país ser constituída por um arquipélago de dez ilhas, a variação linguística da língua gestual usada pelos surdos em Cabo Verde foi um dos grandes desafios na construção desse dicionário. As autoras, que atuaram na edição, preparação e revisão desse empreendimento linguístico em 
Cabo Verde, concluíram e publicaram o dicionário da língua gestual cabo-verdiana em 2019.

\section{A língua gestual guineense}

Assim como acontece com a língua gestual cabo-verdiana, não encontramos documentação oficial referente à língua gestual guineense (LGG) nas buscas pelos canais governamentais e creditamos isso a recente institucionalização da educação de surdos em Guiné-Bissau, como já mencionamos anteriormente. De todo modo, evidenciamos o esforço de padronização da língua gestual empreendido na criação de um dicionário da língua gestual no país. A criação desse dicionário, que contou com a colaboração de Morgado e Martins (2008), teve início em 2005, por meio da indicação da Associação de Surdos de Portugal (ASP) como proposição de ajuda à já mencionada AGRICE, então responsável pela educação de surdos em Guiné-Bissau.

Inicialmente, a ASP encaminhou um material para ensino de LGP. Contudo, ao perceberem que a comunicação sinalizada pelas crianças e jovens surdos guineenses já não tinha influência da língua gestual portuguesa, as autoras entenderam que "os gestos utilizados já permitiam documentar a existência partilhada, por aquele grupo de alunos, de um vocabulário essencialmente concreto e com grande influência cultural" (MORGADO; MARTINS, 2008, p. 16). Com base nas atividades de convivência dos alunos surdos, a equipe do dicionário registrou 200 gestos, o que culminou, mais tarde, na criação da Escola Nacional de Surdos. A partir de uma segunda fase de registros no ano de 2006, cujo cômputo foi de 520 novos gestos registrados, foi possível, em 2008, a publicação do Dicionário Escolar de Língua Gestual Guineense (MARTINI; MORGADO, 2008).

Considerando o desenvolvimento da língua, resultante da promoção do seu uso nos anos subsequentes, em 2017, foi publicado o Dicionário Prático de Língua Gestual Guineense (MARTINI; MORGADO, 2017). Esse segundo dicionário da LGG é resultado do trabalho desenvolvido pela Escola Nacional de Surdos com apoio das associações de surdos em Guiné-Bissau e em Portugal.

\section{A língua de sinais moçambicana}

No contexto de Moçambique, o único documento oficial encontrado que faz menção à língua de sinais moçambicana (LSM) foi a Constituição da República, de 2004. Contudo, não há qualquer descrição nem caracterização da língua de sinais nele, e o documento não contempla a questão da educação de surdos, nem em seus artigos 88 e 113, dedicados ao direito à educação e à educação, respectivamente.

A língua de sinais é mencionada no contexto do art. 125으, denominado Portadores de deficiência, em que se destaca a promoção da criação "de condições para a aprendizagem e desenvolvimento da língua de sinais" (p. 37). Não fica especificado como essa promoção ocorreria nem por quais meios a aprendizagem e desenvolvimento da LSM são ofertados. Interessante notar que, embora a língua de sinais seja mencionada na Constituição de 2004, 
Bavo e Coelho (2019), como já dito, destacam que os censos de 2007 e 2017 não apresentam registros sobre o uso de LSM no país.

Apesar da menção à língua de sinais na Constituição possa ser associado à categoria de reconhecimento constitucional de De Meulder (2015), entendemos que, no caso moçambicano, esse reconhecimento está implícito na Constituição. Isso porque a língua de sinais é tratada pelo documento de forma genérica e não fica evidente o entendimento do Estado em relação ao papel dessa língua no país.

\section{A língua gestual portuguesa}

Considerando o percurso histórico da língua gestual portuguesa, assim como da língua brasileira de sinais, é extensa a bibliografia referente à constituição política dessa língua, algumas das quais já referenciadas neste artigo, do mesmo modo que é extensa a documentação oficial que de algum modo regulamenta o uso da LGP em Portugal. Nesse sentido, selecionamos, três documentos oficiais, uma vez que cada um deles manifesta informações válidas e únicas relacionadas a essa língua e ao ensino bilíngue por meio dela.

O primeiro documento português oficial a fazer menção à língua gestual que destacamos aqui é a Constituição da República Portuguesa de 1976. Em sua revisão de 1997 a Constituição reconhece a língua gestual portuguesa ao designar ao Estado, na alínea h) do número 2 do art. 74으, proteger e valorizar essa língua "enquanto expressão cultural e instrumento de acesso à educação e da igualdade de oportunidades" (p. 26). Apesar de não fazer uma caracterização da LGP, o documento confere destaque à valorização dessa língua como forma de expressão cultural, e pode ser relacionado à categoria de reconhecimento constitucional de De Meulder (2015). De acordo com Coelho e Correia (2014, p. 105):

\footnotetext{
Este reconhecimento da língua gestual portuguesa (LGP) como expressão cultural e instrumento de acesso à educação de crianças e jovens surdos/as esteve na origem de uma progressiva evolução em direção a uma orientação educativa bilíngue (língua gestual portuguesa - língua portuguesa), que, até o presente, teve a sua mais alta concretização no Decreto-Lei no 3/2008 e na Lei no 21/2008, de 12 de maio (1a alteração ao Decreto-Lei no 3/2008).
}

O Decreto-Lei no 3/2008, conforme mencionado pelas autoras, tem como premissa a promoção da qualidade de ensino orientada pela valorização da educação e da igualdade de oportunidades a partir do desenvolvimento de uma escola inclusiva que considere as necessidades educativas especiais com vista a assegurar maior atividade participativa dos alunos. Sendo assim, o documento abrange amplamente a questão da educação bilíngue, ainda que não caracterize a LGP. O documento apresenta em seu art. 18으, sobre adequações curriculares individuais, questões sobre a modalidade de ensino, sendo a adequação do currículo dos alunos surdos apresentada como ensino bilíngue que consiste na introdução de áreas curriculares específicas para a primeira língua (L1), segunda língua (L2) e terceira língua (L3), de tal maneira que a LGP seja ensinada como L1 e a língua portuguesa, como L2 do pré-escolar ao ensino secundário; bem como uma terceira língua escrita seja introduzida 
no terceiro ciclo do ensino básico ao ensino secundário. Ainda sobre o ensino bilíngue, o documento destaca no seu art. 23, sobre educação bilingue de alunos surdos, o dever de que a educação de alunos surdos seja feita em ambientes bilingues que viabilizem o domínio da LGP e do português escrito e, possivelmente, falado, e a concentração de alunos surdos em ambientes de comunidade surda, ensejando uma comunidade linguística de referência.

A Lei no 21/2008 é a primeira alteração feita ao Decreto-Lei no 3/2008, tal qual abarca a educação inclusiva e social que propicia o sucesso educativo e a igualdade de oportunidades. Acerca da educação bilíngue, o documento apresenta alterações que acrescentam, ao Decreto-Lei no 3/2008, o dever das escolas bilíngues de garantir a frequência precoce das crianças surdas à escola e apoio e informação às famílias, além de disponibilizar recursos técnicos especializados e docentes de LGP, os quais devem assegurar o desenvolvimento da língua gestual como primeira língua dos alunos surdos. Uma das principais alterações que a Lei no $21 / 2008$ fez no Decreto-Lei no 3 do mesmo ano é a remoção da exclusividade surda na docência de LGP, permitindo que a essa língua passasse a ser ensinada também por professores ouvintes. Essa modificação tem um impacto significativo na educação de surdos em Portugal: assim como ocorre em Brasil, crianças surdas portuguesas passam a ter, como possibilidade de referencial cultural e linguístico, a figura ouvinte. Essa tem sido uma questão delicada nas discussões sobre educação de surdos nos dois países que carece de mais investigações.

\section{A língua gestual de São Tomé e Príncipe}

Assim como nos casos de Cabo Verde e de Guiné-Bissau, não localizamos documentos oficiais que mencionam a língua gestual de São Tomé e Príncipe (LGSTP). Não obstante, constamos a menção à Educação Especial na Lei no 2/2003, a Lei de Bases do Sistema Educativo, em seus artigos 17, sobre âmbito e objetivos da Educação Especial, e 18, sobre a organização da Educação Especial. Contudo, o documento não apresenta especificações da educação de surdos.

De todo modo, como nos casos anteriores mencionados, identificamos a existência do Dicionário da Língua Gestual de São Tomé e Príncipe (CARMO; OLIVEIRA; MINEIRO, 2014). A criação do dicionário é proveniente da necessidade por uma melhora na qualidade de vida da população surda de São Tomé e Príncipe, a qual era submetida ao isolamento social devido à ausência de uma língua propícia à comunicação. De acordo com Mineiro e Carmo (2016), urgia a estruturação de bases emergentes para uma língua gestual. Segundo as autoras, as crianças surdas do país se encontravam sistematicamente rejeitadas pelas escolas em virtude de professores não conseguirem ter uma relação linguística com elas (MINEIRO; CARMO, 2016).

A criação do dicionário foi de competência do Projeto Sem Barreiras, promovido por uma parceria entre o Governo de São Tomé e Príncipe, o Hospital CUF Infante Santo, o Instituto Marquês de Valle Flôr e a Universidade Católica Portuguesa, o qual objetivou promover encontros sistemáticos entre surdos - que, antes do projeto, tinham pouco ou 
nenhum contato entre si. Devido à insuficiência de fundos para amparar toda a população surda são-tomense, o projeto anteferiu por pessoas de idade tenra e com surdez profunda uma vez que eram impossibilitadas de frequentar o ambiente escolar. Sendo assim, foi assegurado que as crianças e jovens interagissem e fomentassem uma língua gestual em comum através do contato sociocomunicativo, o que culminou no recolhimento e registro de um vocabulário gestual comum durante os anos de 2012 e 2013.

\section{A língua gestual timorense}

Do mesmo modo que Cabo Verde, Guiné-Bissau e São Tomé e Príncipe, não localizamos documentos oficiais que, de algum modo, referenciem a língua gestual timorense nem que regulamentem o seu ensino. Verificamos que o art. 59, sobre Educação e Cultura, da Constituição da República Democrática de Timor Leste, de 2002, não abrange a educação especial. Essa ausência de informações oficiais sobre os surdos e a língua de sinais timorense, para Ana Isabel da Silva (2011), está relacionada com o pouco conhecimento existente sobre a comunidade surda do país.

Em junho de 2019, o Ministério da Educação, Juventude e Desporto, juntamente com o Ministério da Solidariedade e Inclusão, organizou um colóquio sobre a língua gestual. 0 objetivo do evento, que contou com o apoio da Embaixada da Austrália em Timor-Leste, foi registrar opiniões dos usuários da língua gestual e professores sobre a forma como deve ocorrer a implementação de seu ensino no sistema educacional do país. Entendemos que essa atenção dada pelo Governo timorense em relação à língua gestual usada no país é fundamental para o início de uma constituição política da língua.

Até aqui, destacamos os principais resultados encontrados no mapeamento de políticas linguísticas para surdos nos países de língua portuguesa. Na sequência, apresentamos nossas considerações sobre esses destaques na documentação oficial selecionada para esta discussão.

\section{Considerações finais}

Neste artigo, intentamos discutir sobre políticas linguísticas para surdos em oito países considerados países de língua portuguesa. Em alguns deles, a língua portuguesa ocupa a posição não só de língua oficial, como também de língua materna de muito dos cidadãos. Em outros, ela é uma segunda língua para muitos e figura como língua cooficial ao lado das línguas nativas. Para tanto, caracterizamos, de forma breve, o contexto histórico das línguas de sinais nesses países; descrevemos o percurso da pesquisa em políticas linguísticas para surdos em uma perspectiva transnacional; e destacamos os resultados encontrados a partir da busca e seleção de documentos oficiais que referenciem as línguas de sinais, os surdos ou à educação de surdos em cada um desses países.

Dos oito países analisados, quatro deles (Angola, Brasil, Moçambique e Portugal) apresentam documentação oficial que, de alguma forma, regulamenta o uso de uma língua 
de sinais em seus territórios nacionais; os outros quatro (Cabo Verde, Guiné-Bissau, São Tomé e Príncipe e Timor-Leste) ainda não apresentam documentação oficial que regulamente o uso ou o ensino de uma língua de sinais, embora seja possível evidenciar esforços para documentação, padronização e promoção dessa língua, muitas vezes em cooperação internacional.

Diante da materialidade analisada, queremos destacar duas questões fundamentais referentes às políticas linguísticas para surdos: o ensino das línguas de sinais e a implementação da educação bilíngue para surdos. A educação bilíngue, um direito defendido por pesquisas linguísticas e educacionais, bem como pelos movimentos surdos, não está materializada em todos os países pesquisados. Em Brasil e em Portugal, cujas estruturas independentes de governo têm mais longevidade, encontramos descrições detalhadas sobre o funcionamento da educação bilíngue para surdos e sobre o ensino das línguas de sinais na formação de professores, assim como também sobre a formação de professores de língua de sinais e de tradutores e intérpretes dessas línguas. É importante ressaltar que alguns desses países têm seus contextos da história legislativa, do cenário social, político e econômico ainda muito recentes, de forma que algumas línguas de sinais enfrentam processos de estandardização e de propagação ainda bastante iniciais.

No entanto, é veemente destacar que as comunidades surdas desses países, como constatado, por vezes são mantidas no isolamento - linguístico e escolar - devido à impossibilidade de partilha de um código em comum com professores e outros profissionais. Sobretudo, entendemos que a insuficiência de políticas que pautem a língua de sinais e a educação de surdos contribui para dificultar a formação e a profissionalização de tradutoresintérpretes e de professores especializados nessas línguas, resultando na precarização das condições de vida das pessoas surdas. A falta de suporte para a criação e manutenção de uma língua comum tende a ferir a liberdade linguística e a percepção identitária, subjetiva e cultural dos sujeitos. Entendemos, também que essas características evidenciadas são reflexo da colonização, como parte da impossibilidade de efetivação de políticas linguísticas para surdos em alguns desses países cujos contextos legislativos são relativamente recentes.

Portanto, incumbe pautar a insuficiência da prática de registros e documentação de gestos e de sinais que compõem algumas das línguas gestuais e de sinais abordadas, o que culmina na ausência de uma legislação inclusiva e congruente ao âmbito da educação especial bilíngue, além da não materialização completa, do não reconhecimento e da não regulamentação dessas línguas em seus Estados-nação. Considerando a discussão proposta, é possível identificar as relações de prestígio e proximidade na forma com a qual o Estado escolhe executar - e, principalmente, não executar - políticas linguísticas voltadas para as comunidades surdas. Como visto, alguns dos países pesquisados ainda adotam a língua gestual portuguesa como norteadora de suas práticas educativas a partir de investidas em formação de professores e outras. E, ao fazê-lo, evidencia a continuidade de uma relação de dominância histórica, e como essa relação - que é, essencialmente, uma relação de poder - está enviesada com as práticas e relações linguísticas das línguas gestuais e de sinais.

Entendemos também que a instituição de políticas linguísticas para surdos, apesar de 
extremamente necessária, não é suficiente para garantir mudanças no comportamento social que visem a inclusão dos surdos na vida em sociedade. Contudo, entendemos que essas políticas linguísticas configuram condições de possibilidade para o exercício da cidadania pelos surdos. Posto isso, e com base nos resultados obtidos na pesquisa aqui apresentada, urge o estímulo de políticas que viabilizem e visibilizem as condições linguísticas e educacionais dos das pessoas surdas, pautando e promovendo suas línguas de sinais. Além disso, evidenciamos a necessidade de produção de mais investigações para conhecer a situação linguística dos surdos, principalmente, em Cabo Verde, Guiné-Bissau, São Tomé e Príncipe e Timor-Leste. Assim como Hlibok (2018) propôs, esperamos, com a discussão aqui desenvolvida, contribuir para o debate e, sobretudo, ampliar as noções sobre os diferentes níveis de reconhecimento das línguas de sinais.

\section{Referências}

ANGOLA. Resolução no 1/13: Adesão de Angola à Convenção sobre os Direitos das Pessoas com Deficiência. Diário da República: Assembleia Nacional. 11 jan. 2013.

ANGOLA. Lei no 10/16 de 27 de julho de 2016. Diário da República. I série, № 125. 27 jul. 2016.

ARAúJO, G. A.; AGOSTINHO, A. L. S. Padronização das línguas nacionais de São Tomé e Príncipe. Línguas e Instrumentos Linguísticos, Campinas, n. 26, p. 49-81, 2010.

AZEVEDO, M. J. S. Mapeamento e contribuições linguísticas do professor surdo aos índios surdos da etnia Sateré-Mawé na microrregião de Parintins. 2015. 115 f. Dissertação (Mestrado Profissional em Letras e Artes) - Programa de Pós-Graduação em Letras e Artes, Universidade do Estado do Amazonas, Manaus, 2015.

BÄR, E. C.; RODRIGUES, C. S.; SOUZA, R. M. Quando a política linguística se funda na noção de deficiência: circularidade nos textos das leis e a ilusão da garantia de direitos linguísticos. Revista Digital de Políticas Linguísticas, v. 10, p. 103-125, 2018.

BAVO, N.; COELHO, O. Pertinência e urgência da língua de sinais (L1) e do português (L2/LE) no currículo dos alunos surdos em Moçambique. Revista e-Curriculum, São Paulo, v. 17, n. 3, p. 909-932, 2019. https://doi.org/10.23925/1809-3876.2019v17i3p909-932

BENVENUTO, A.; SÉGUILLON, D. Primeiros banquetes dos surdos-mudos no surgimento do esporte silencioso. 1834-1942: por uma história política das mobilizações coletivas dos surdos. Moara, n. 45, p. 60-78, 2016. https://doi.org/10.18542/moara.v1i45.3707

BRASIL. Lei no 10.436 de 24 de abril de 2002. Diário Oficial da República Federativa do Brasil: Brasília, DF. 25 abr. 2002.

BRASIL. Decreto no 5.626 de 22 de dezembro de 2005. Diário Oficial da República Federativa do Brasil: Brasília, DF. 22 dez. 2005.

CALVET, L-J. As políticas linguísticas. São Paulo: Parábola Editorial, 2007.

CARMO, P.; OLIVEIRA, R.; MINEIRO, A. Dicionário da Língua Gestual de São Tomé e Príncipe. Lisboa: Universidade Católica Editora, 2014.

CARVALHO, P. V. O Abade de L’Epée no século XXI. In: JORNADAS DE LíNGUA GESTUAL 
PORTUGUESA - LÍNGUA, ENSINO E INTERPRETAÇÃO, 1, 2012, Coimbra. Anais... Coimbra: ESEC, 2012. Disponível em:

http://www.porsinal.pt/index.php?ps=artigos\&idt=artc\&cat=7\&idart=307. Acesso em: 26 out. 2020.

CARVALHO, P. V. A emergência do léxico especializado na língua gestual portuguesa: proposta de construção de um dicionário terminológico bilíngue-bidirecional online. Revista Ideação, Foz do Iguaçu, v. 18, n. 1, p. 12-42, 2016.

COELHO, O.; CORREIA, F. S. Revolução de abril, educação de surdos/as e ensino da filosofia: da deficiência à pertença cultural. Educação, Sociedade e Cultura, Porto, n. 43, p. 103-119, 2014.

DE MEULDER, M. The Legal Recognition of Sign Languages. Sign Language Studies, v. 15, n. 4, p. 498-506, 2015. https://doi.org/10.1353/sls.2015.0018

FERREIRA-BRITO, L. Similarities and differences in two Brazilian Sign Language. Sign Language Studies, v. 42, p. 45-56, 1984. https://doi.org/10.1353/sls.1984.0003

FREIXO, A. Minha pátria é a língua portuguesa: a construção da ideia de lusofonia em Portugal. Rio de Janeiro: Apicuri, 2009.

FUSELLIER-SOUZA, I. Sémiogenèse de langues des signes. Etude de Langues de Signes Emergentes (LSE) pratiquées par de sourds brésiliens. 2004. 416 f. Tese (Doutorado em Sciences du Langage) - École Doctorale Cognition, Langage, Interaction, Université Paris 8, Paris, 2004.

GIROLETTI, M. F. P. Cultura surda e educação escolar Kaingang. 2008. 219 f. Dissertação (Mestrado em Educação) - Programa de Pós-Graduação em Educação, Universidade Federal de Santa Catarina, Florianópolis, 2008.

HLIBOK, T. H. Language Policy in Context of Sign Languages and Deaf Community Activism. Llengua, Societat i Comunicació, n. 16, p. 54-62, 2018.

LODI, A. C. B. Educação bilíngue para surdos e inclusão segundo a Política Nacional de Educação Especial e o Decreto no 5.626/05. Educação e Pesquisa, v. 39, n. 1, p. 49-63, 2013. https://doi.org/10.1590/S1517-97022013000100004

MARTINI, M.; MORGADO, M. Dicionário Escolar de Língua Gestual Guineense. Lisboa: Surd'Universo, 2008.

MARTINI, M.; MORGADO, M. Dicionário Prático de Língua Gestual Guineense: língua gestual guineense para todos. Lisboa: Surd'Universo, 2017.

MARTINS, M. Documentário sobre a Língua de Sinais da Guiné-Bissau. In: CONGRESSO INTERNACIONAL DO INES E SEMINÁRIO NACIONAL DO INES, 12; 18, 2013, Rio de Janeiro. Anais... Rio de Janeiro: INES, 2013. p. 121-123. https://doi.org/10.24220/23180870v21n2a3277

MARTINS, V. R. O.; LACERDA, C. B. F. Educação inclusiva bilíngue para surdos: problematizações acerca das políticas educacionais e linguísticas. Revista de Educação, Campinas, v. 21, n. 2, p. 163-178, 2016.

MINEIRO, A.; CARMO, P. Língua Gestual de São Tomé e Príncipe: retrato dos primeiros gestos. Revista de Estudos Linguísticos da Universidade do Porto, Porto, v. 11, p. 161-182, 2016. 
MORGADO, M.; MARTINS, M. Uma investigação na Guiné-Bissau: o nascimento da língua gestual. Boletim Rede Inclusão, n. 1, p. 16-16, jul. 2008.

MOÇAMBIQUE. Constituição da República de Moçambique de 2004. Promulgada em 24 de novembro de 2004.

PALHA, S.; MINEIRO, A. Ensino de português a surdos em São Tomé e Príncipe: de um paradigma de exclusão até a inclusão. Revista de Educação Especial, Santa Maria, v. 32, n. 64, p. 1-13, 2019. https://doi.org/10.5902/1984686X38355

PAVÃO, A. C. O.; GOMES, A. P. G.; CASARIN, M. M. Dicionário da língua gestual caboverdiana. Santa Maria: Facos-UFSM, 2019.

PEREIRA, E. L. "Fazendo Cena na cidade dos mudos": surdez, práticas sociais e uso da língua em uma localidade no sertão do Piauí. 2013. 418 f. Tese (Doutorado em Antropologia Social) - Programa de Pós-Graduação em Antropologia Social, Universidade Federal de Santa Catarina, Florianópolis, 2013.

PORTUGAL. Constituição da República Portuguesa de 1976. Promulgada em 25 de abril de 1976. Revisão de 1997.

PORTUGAL. Decreto-Lei no 3/2008 de 7 de janeiro de 2008. Diário da República. 1. a série. № 4-7. 7 jan. 2008.

PORTUGAL. Lei no 21/2008 de 12 de maio de 2008. Diário da República. 1.a série. № 91.12 maio 2008.

QUADROS, R. M. Language Policies and Sign Languages. In: TOLLEFSON, J.; PÉREZ-MILLANS, M. (Eds.). The Oxford Handbook of Language Policy and Planning. Oxford University Press: Oxford, 2018. p. 1-23.

QUADROS, R. M. Libras. São Paulo: Parábola, 2019.

QUADROS, R. M.; CAMPELLO, A. R. S. A constituição política, social e cultural da língua brasileira de sinais - Libras. In: VIEIRA-MACHADO, L. M. C.; LOPES, M. C. (Orgs.). Educação de surdos: políticas, língua de sinais, comunidade e cultura surda. Santa Cruz do Sul: EDUNISC, 2010. p. 15-47.

RODRIGUES, C. H.; BEER, H. Direitos, políticas e línguas: divergências e convergências na/da/para educação de surdos. Educação \& Realidade, Porto Alegre, v. 41, n. 3, p. 661-680, 2016. https://doi.org/10.1590/2175-623661114

RODRIGUES, J. R.; VIEIRA-MACHADO, L. M. C. Primeiro Congresso Nacional para o Melhoramento das Condições dos Surdos-mudos - Lyon - 1879. Revista História da Educação, v. 23, e93873, p. 1-25, 2019.

SANTOS, A. N.; COELHO, O.; KLEIN, M. Educação de surdos no Brasil e Portugal: políticas de reconhecimento linguístico, bilinguismo e formação docente. Educação e Pesquisa, v. 43, n. 1, p. 215-228, 2017. https://doi.org/10.1590/s1517-9702201608148639

SANTOS, M. M.; SOUSA, H. C. A. Língua gestual de Timor-Leste - a língua que falta em TimorLeste para a participação dos surdos timorenses no desenvolvimento do seu país. In: PAULINO, V.; SANTOS, M. M. (Orgs.). Língua e linguagem no cotidiano. Díli: UNTL, 2017. p. 103-118.

SILVA, A. I. P. P. E se eu fosse s/Surda? O processo de categorização do mundo da pessoa 
s/Surda: a perspectiva da linguística cognitiva. 2011. $701 \mathrm{f}$. Tese (Doutorado em Linguística e Ensino de Línguas) - Programa de Pós-Graduação em Línguas e Literaturas Modernas, Universidade Católica Portuguesa, Viseu, 2011.

SPOLSKY, B. Para uma Teoria de Políticas Linguísticas. ReVEL, v. 14, n. 26, p. 32-44, 2016.

STOKOE, W. Sign Language Structure: An Outline of the Visual Communication Systems of the American Deaf [1960]. Journal of Deaf Studies and Deaf Education, v. 10, n. 1, p. 3-37, 2005.

TEMÓTEO, J. G. Diversidade linguístico-cultural da Língua de Sinais do Ceará: um estudo lexicológico das variações da Libras na comunidade de surdos do Sítio Caiçara. 2008. 167 f. Dissertação (Mestrado em Letras) - Programa de Pós-Graduação em Letras, Universidade Federal da Paraíba, João Pessoa, 2008.

TAVARES, H. A. L. Educação de surdos em países do continente africano - relato da situação de Cabo Verde. In: CONGRESSO INTERNACIONAL DO INES E SEMINÁRIO NACIONAL DO INES, 12; 18, 2013, Rio de Janeiro. Anais... Rio de Janeiro: INES, 2013. p. 65-68.

THOMA, A. S. Educação bilíngue nas políticas educacionais e linguísticas para surdos: discursos e estratégias de governamento. Educação \& Realidade, Porto Alegre, v. 41, n. 3, p. 755-775, 2016. https://doi.org/10.1590/2175-623661087

VANALI, A. C. Datilologia nos países de língua portuguesa. Revista NEP, Curitiba, v. 2, n. 5, p. 159-170, 2016. https://doi.org/10.5380/nep.v2i5.49566

VILHALVA, S. Índios surdos: mapeamento das línguas de sinais do Mato Grosso do Sul. Petrópolis: Arara Azul, 2012.

VIÚME, F. S. F. Educação de surdos em países do continente africano / A educação dos surdos em Angola. In: CONGRESSO INTERNACIONAL DO INES E SEMINÁRIO NACIONAL DO INES, 12; 18, 2013, Rio de Janeiro. Anais... Rio de Janeiro: INES, 2013. p. 69-78.

Recebido em: 20/04/2020. Aceito em: 03/07/2020. 